This item was submitted to Loughborough's Institutional Repository (https://dspace.lboro.ac.uk/) by the author and is made available under the following Creative Commons Licence conditions.

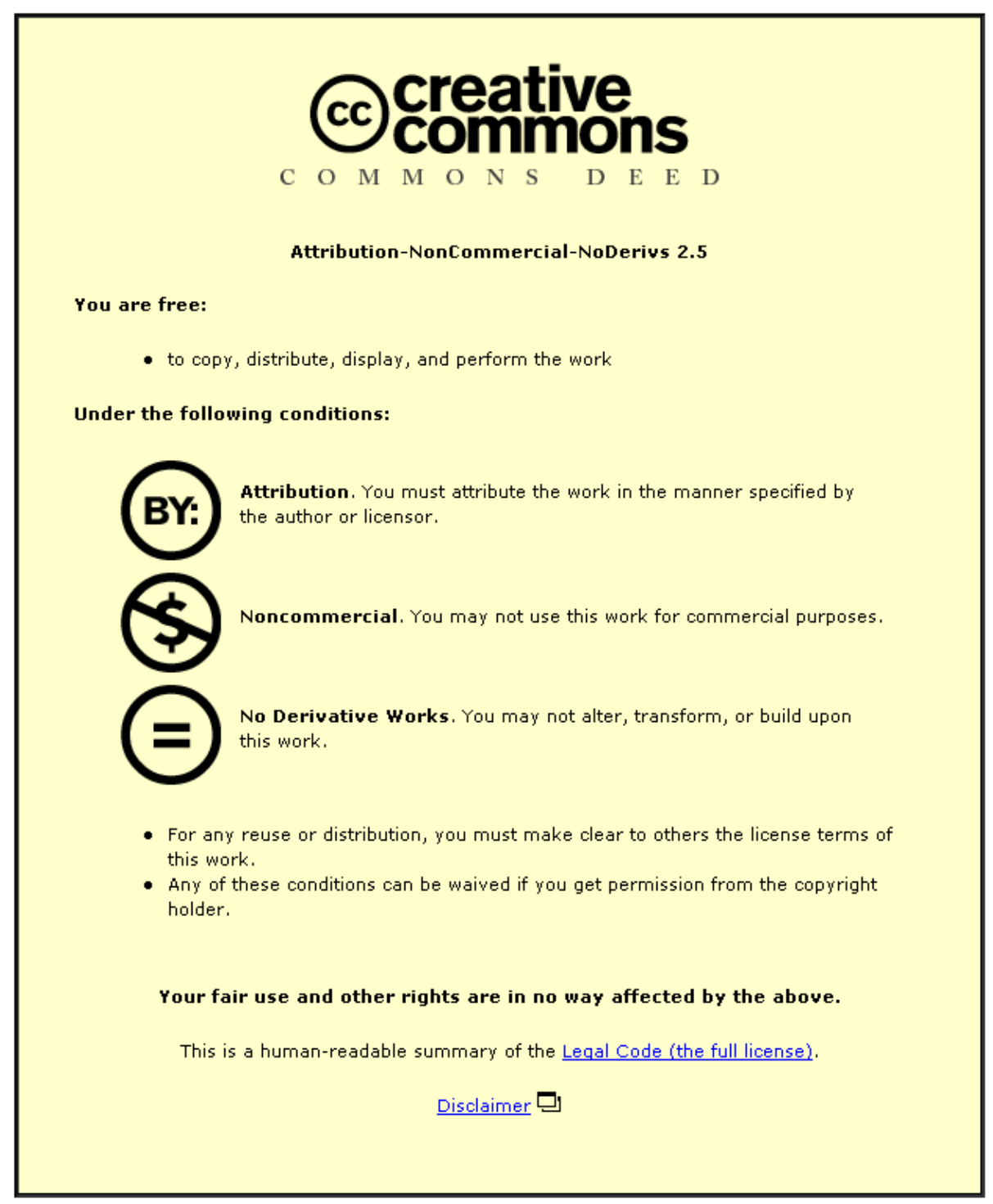

For the full text of this licence, please go to: http://creativecommons.org/licenses/by-nc-nd/2.5/ 


\title{
The role of social relationships in improving product development decision making
}

\author{
S C Morton $^{1 *}$, N J Brookes ${ }^{2}$, A R J Dainty ${ }^{3}$, C J Backhouse ${ }^{4}$, and N D Burns ${ }^{1}$ \\ ${ }^{1}$ Wolfson School of Mechanical and Manufacturing Engineering, Loughborough University, Loughborough, UK \\ ${ }^{2}$ Innovation Leadership Centre, Cranfield University, Cranfield, UK \\ ${ }^{3}$ Department of Civil and Building Engineering, Loughborough University, Loughborough, UK \\ ${ }^{4}$ Faculty of Engineering, Loughborough University, Loughborough, UK
}

The manuscript was received on 18 August 2005 and was accepted after revision for publication on 4 January 2006.

DOI: 10.1243/09544054JEM451SC

\begin{abstract}
The quality of decision making in product development (PD) is dependent upon the designer's ability to optimize conflicting needs. However, optimization is unlikely to succeed when based on inaccurate or erroneous information. Given that provision of accurate information frequently lies beyond the designer, decision making is dependent upon effective optimization and a timely flow of accurate information. The present paper explores informal organizational approaches to improving information flow for decision making. It presents an empirical study of relationships in two UK engineering companies and finds significant correlation between the effectiveness of these relationships and the trust, respect, and loyalty that they exhibit during PD. It further identifies the impact of relationship longevity, commonalty in background, and the wider social context of relationships. It concludes by examining the potential extendibility of the findings and the potential for further research to identify interventions that can assist management to enhance the relationships of product developers.
\end{abstract}

Keywords: product development, empirical research, social network analysis, performance improvement

\section{INTRODUCTION}

Product design and product development (PD) can be viewed as decision-making processes [1]. At the start of the development process no aspect of the product is defined, the overall concept for the design being reached by a series of decision-making activities. Further decisions enable the detailed design to be completed and the information required for manufacturing, assembling, and testing the final product to be generated. At the end of the development process, all of the information required to create the product in question will have been brought into existence by a series of decisionmaking processes undertaken by the product designers and developers. These decisions will have

${ }^{*}$ Corresponding author: Wolfson School of Mechanical and Manufacturing Engineering, Loughborough University, Loughborough LE11 3TU, UK. email: s.c.morton@lboro.ac.uk ranged in significance from fundamental product attributes to comparatively minor decisions [2].

Pugh [3] identifies over thirty, potentially conflicting, characteristics and attributes that a product will need to satisfy. The quality of decision making will depend on how good the designer is at reconciling and optimizing in a situation of conflicting needs. While sophisticated approaches to optimization are within the reach of industrial applications through a combination of new optimization methods, these will not succeed if they are based on inaccurate or erroneous information. Provision of this information is often beyond that of the designer, with the result of frequently being forced to make decisions on the development of the product that lie beyond immediate personal expertize. Eppinger and Salimen have stated that design is a social process $[\mathbf{1}]$. The implications are that decision making in PD is not only dependent upon effective optimization, but also on a timely flow of accurate 
information from many people. This paper explores the social processes that underlie the effectiveness of communication flow within the context of the PD process.

\section{RESEARCH CONTEXT}

A significant and lengthy antecedent for information being used to improve decision-making performance exists in fields as diverse as marketing [4] and production control [5], and one of the prime functions of information technologies is in supporting decision making at all levels of the organization [6]. Snowden [7] characterized the first wave of knowledge management as having a focus on timely information provision, while Eppinger [8] has stated that 'the exchange of information is the lifeblood of product development'.

The use of formal organizational structures to influence flow of information has a similarly lengthy antecedent, to the extent of regarding organizations as information-processing structures [9-11]. This is also true for PD [12]. The need to improve information flow implicitly underlies one of the most widespread organizational mechanisms used to improve PD: cross-functional teams (CFTs). Formally recognized units in the organizational structure, CFTs bring people from various disciplines into one organizational entity, and form one of the key manifestations of concurrent engineering [13]. McDonagh [14] highlights their widespread prevalence in an overview on the considerable body of literature investigating their operation. CFTs enhance information flow by removing formal organizational and spatial boundaries between people.

While CFTs have been associated with significant improvements in PD performance, the need for further research into the operationalization of CFTs has been identified (e.g. [15]). Issues relating to total system performance have been reported (e.g. [16] [17]) that focus on aspects of organizational learning and the remaining PD activities that are difficult to disperse into teams: PD's 'functional rump'. Furthermore, Henderson [18] has suggested that formal organization structure is not the prime determinant of PD success. Instead she identified that companies that developed mechanisms for overcoming formal organizational boundaries were more effective at developing products. This suggests that another aspect of organizational structure may be a significant factor in the successful transfer of information in PD.

Unlike formal organizational interventions, the impact of the informal organization on information flow during PD has not been similarly investigated. The answer to this conundrum raised by Henderson's research may lie in the interrelationships that underlie the social capital held within an organization. Thus, attempts to improve PD performance must not be confined to formal, structural aspects of organization. This research postulates that improving the social capital within the PD organization will enable more effective decision making through improved flows of information.

\subsection{Social capital and its role in information exchange}

Social capital is a concept of increasing importance in understanding the antecedents of organizational performance. Nahapiet and Ghoshal construe social capital as 'the sum of actual and potential resources embedded within, available through and derived from the network of relationships possessed by a social unit' [19]. Cohen and Prusak have defined social capital as consisting of 'The stock of active connections among people: the trust, mutual understanding and shared values and behaviours that bind the members of human networks and communities and make co-operative action possible' [20]. Both definitions highlight that the building block of social capital lies in the dyadic relationship between two individuals. Thus, any attempt to improve social capital must start at this level.

Interrelationships have been identified as key in enhancing or constraining access to valued resources such as information [21] [22]. Hence, such relationships may have an important role to play in facilitating the flow of information and hence the decision-making process during PD. It is important that the individual-to-individual nature of these relationships is recognized. Bouty [23], for example, highlights the key role that relationships have in the flow of technologies across organizations and emphasizes the role of 'heart partners', where the levels of trust are so deep in a relationship that information is exchanged regardless of each other's professional affiliations. However, it should be noted that relationships that are high in trust are not always beneficial. While Florida [24] highlights the potentially stifling effect of social capital, Hansen [25] shows that weak ties are better than strong ones for gathering information. Overembeddedness within a team may also occur and reduce the flow of new ideas to PD [26]. Nevertheless, Athaide and Stump [27] have created a taxonomy of relationships with respect to information flow during the PD process. A longitudinal investigation into PD in the UK automotive industry has also been undertaken using thematic analysis of interviews with a cross-section of people involved 
in the PD process [28-30]. The research findings showed that:

(a) personal relationships were identified as very important for successful PD;

(b) these relationships had longevity and lasted over many project cycles and changes in the formal organizational structure;

(c) antecedents for effective relationships were identified that included trust, respect, loyalty, common background and experience, and shared social contexts.

\subsection{The determinants of effective relationships in PD}

Previous work outlined in the current paper has shown that effective relationships in PD are founded upon trust, respect, and loyalty. The importance of trust in effective relationships has also been highlighted [23], [27-30]. Trust is a concept that has received much attention in the management literature exemplified by the work of Meyerson et al. [31], Hardt and Brynteson [32], and Jarvenpaa et al. and Jarvenpaa and Staples [33, 34]. The type of trust that is being described in these investigations is 'prediction based', defined as the extent to which the person who trusts can predict that the person trusted will act in good faith [35]. Thus, the first hypothesis of the research is that effective relationships between product developers positively correlate with the levels of trust between the developers (H1), where 'effective' is defined as:

(a) having a definite or desired effect;

(b) efficient, where - in turn - 'efficient' is defined as (i) productive with minimum waste or effort and (ii) (of a person) capable, acting effectively [36].

The importance of loyalty and respect as concepts highlighted by the UK automobile manufacturer study are not as well developed in the literature as trust. Loyalty is a concept more often associated with loyalty to a particular organization or to a particular brand [37] [38], with customer loyalty and its promulgation a key concept in marketing terms. Loyalty as a concept also comes into play in analysing employees' attitudes to their employing organization: organizational loyalty. Loyalty between individuals, the concept of personal loyalty, has not been widely explored, although its close associate, 'cronyism', has been investigated [39]. Therefore, it is also hypothesized that effective relationships between product developers positively correlate with the levels of loyalty in the relationships (H2).

Respect is a conceptual term that, as with loyalty, has not undergone the same degree of explor- ation as trust, although its importance in effective operations has begun to be considered, particularly in the context of 'turnarounds' [39]. Thus, the third hypothesis is that effective relationships between product developers positively correlate with the levels of respect in the relationships (H3).

In determining the antecedents of trust, loyalty, and respect, extant research has emphasized the importance of the relationship longevity in building its success [22], [23], [28-30]. Thus, this research also hypothesizes that longevity of relationships between developers positively correlates with relationship effectiveness (H4). Further, the importance of a similar professional background and of a wider social context for the relationship have also been highlighted [23], [28-30]. Therefore, the penultimate hypothesis is that a shared common background between developers positively correlates with relationship effectiveness (H5), and the final hypothesis is that the relationships between developers in a wider social context positively correlate with relationship effectiveness (H6).

\section{RESEARCH METHOD}

The aim of the present investigation is to study the antecedents of effective relationships during PD using the research context delineated in the section above.

\subsection{The sample population}

The sample population comprised 76 different individuals involved in product development projects in two UK engineering organizations. The impact of macro-level characteristics of the specific industry upon the characteristics of the teams in which these individuals are employed requires that they are able to assimilate and incorporate a wide variety of information that resides with people outside of their work-unit. The providers of such information are not only proximate to their own physical location, but often exist across geographical and organizational boundaries. The teams frequently need to surmount the inherent communication barriers caused by the global dispersal of their own members, while simultaneously existing in the complex hierarchy of teams that comprise the total product development activity for a new product. In this situation, developing relationships that enable a good flow of information is crucial to the success of the team(s). Table 1 provides a breakdown of the sample population by team within organization.

The sample comprised a different population group than the automotive sector investigation referred to previously and the backgrounds of the individuals were in design engineering, manufactur- 
ing engineering, or in technical purchasing. Their roles within the organizations focused solely on new product development, i.e. they were not involved in operational support to on-going production. Respondents were selected first by identifying projects within the organization that were typical of its activity in terms of lead time, complexity, customer, and then by identifying individuals working on those projects to act as the sample population.

\subsection{Data collection process}

The type of data required was of a highly sensitive nature, with individuals being asked about very personal aspects of their relationships with colleagues: trust in/respect for each other, for example. Accordingly a data collection process that emphasized confidentiality was adopted. This also meant that the sample companies needed to have a culture of openness and approachability and supported an environment that would provide researchers with access to sensitive information. The process began with a formal presentation to the investigation subjects that emphasized the confidentiality of their individual responses and the separate affiliation from any other management agenda. It was also important to ensure that the subjects shared a common understanding with the research team of the terms used in the data collection process. For example, 'trust'

Table 1 Characteristics of the sample population

\begin{tabular}{llll}
\hline Organization & Description & Team & Participants \\
\hline A & Aerospace engineering & 1 & 10 \\
& corporation & 2 & 11 \\
& & 3 & 9 \\
& 4 & 4 \\
B & & 6 \\
& Design engineering & 1 & 5 \\
& consultancy & 2 & 5 \\
& 3 & 6 \\
& 4 & 12 \\
& 5 & 9 \\
\hline
\end{tabular}

was defined here as the extent to which the subject can predict that his/her contact will act in good faith, and effectiveness as the success of that interaction in transferring the required information and resources. This was achieved by explanation of the instruments to be used, how these should be completed, and the process for operationalizing the variables (see Table 2). Each participant was provided with a written questionnaire on which to record their data and was asked to return the questionnaire directly to the research investigators. In order to confirm that responses were not skewed, the distribution of responses against each variable was also examined.

The questionnaire used relationships with individuals during the PD process as its unit of analysis. Subjects were asked to identify individuals with whom they interacted during PD and to rate each relationship in terms of its effectiveness, trust, respect, and loyalty. The subject was also asked to provide details of the relationship's age, the degree to which that person had a similar background, and whether the relationship had a context outside the work environment. Using this procedure, data were collected on over 1000 relationships.

\subsection{Operationalizing the variables}

The approach adopted to operationalize the variables emulated that of similar projects by allowing individual interpretation of rating value within given guidelines [40]. Table 2 shows how ratings on the variables were elicited by the questionnaire.

Operationalizing the variables in a study such as this could arguably have been achieved by utilizing multiple-item rather than single-item constructs. This is the logic of 'domain sampling' [41], the implications of which are that measures with more items are more reliable [42]. Researchers use responses to a series of related questions to form a single measure of trust, for instance, rather than asking an actor directly how much he or she trusts the other actor in the relationship. However, in

Table 2 Operationalization of the variables

\begin{tabular}{|c|c|c|}
\hline Question & Scale & Variable \\
\hline $\begin{array}{l}\text { In terms of achieving results, which of the following best } \\
\text { describes the effectiveness of your relationship? }\end{array}$ & 1) Not at all; 2) Not very; 3) Fairly; 4) Very effective & Effectiveness \\
\hline $\begin{array}{l}\text { How much do you trust this person will carry out } \\
\text { what you expect in this relationship? }\end{array}$ & 1) Not at all; 2) Not very; 3) Fairly; 4) Very much & Trust \\
\hline $\begin{array}{l}\text { Based on your shared interactions, to what extent do } \\
\text { you have feelings of loyalty for this person? }\end{array}$ & 1) Not at all; 2) Not very; 3) Fairly; 4) Very much & Loyalty \\
\hline $\begin{array}{l}\text { In terms of the role they perform, how much do you } \\
\text { respect this person's knowledge and experience? }\end{array}$ & 1) Not at all; 2) Not very; 3) Fairly; 4) Very much & Respect \\
\hline How old is your relationship with this person? & 1) $<1$ year; 2) 1-2 years; 3) 3-4 years; 4) $>=5$ years & Longevity \\
\hline $\begin{array}{l}\text { Do you share a common background, history, or } \\
\text { shared interests with this person? }\end{array}$ & 1) Don't know; 2) Few; 3) Some; 4) Many commonalties & Commonalty \\
\hline Do you meet this person outside work? & 1) Never; 2) Sometimes; 3) Frequently & Social context \\
\hline
\end{tabular}


pilot investigations researchers had identified a sub sample of participants and compared the correlation between responses with a single-item and multipleitem approach to rating variables [43]. The singleitem measurement correlated significantly with the multiple-item measurement, which gave the researchers the confidence to operationalize the variables under scrutiny in this investigation with single rather than multiple constructs.

Researchers also asked participants to self-rate the properties of their relationships. Although self-rating would not usually be utilized without some 'objective' confirmatory rating, it was necessary to rely on self-rating alone in this context as the effectiveness of a relationship, for example, is a subjective concept and is rooted in the self-perception of the informant. This can be illustrated by way of a dyadic relationship comprising persons ' $\mathrm{X}$ ' and ' $\mathrm{Y}$ '. It is perfectly possible for ' $\mathrm{X}$ ' to see the relationship as very effective while ' $\mathrm{Y}$ ' perceives the relationship with ' $\mathrm{X}$ ' to be far from effective. Such differences in perception can provide a valuable insight to the individual, team, or organization performance overall. To this end, self-rating of some variables is necessary, which is reflected by other similar investigations of social concepts that have resorted to self-rating measurements (see reference $[41])$.

\subsection{Data analysis methods}

In order to check that responses were neither skewed nor demonstrated a restricted variance, frequency histograms were plotted for each of the variables that demonstrated a sufficiently large variance to indicate that investigation subjects were showing a range of responses and therefore were likely not to be self-censoring. The data collected were ordinal in nature and were assumed to be non-parametric in their distribution. Spearman's co-efficient of correlation [44] is a suitable test for correlation between variables of this type. The significance and magnitude of correlation was also tested.

\section{RESULTS AND ANALYSIS}

Figure 1 shows the respective distribution of responses for the variables effectiveness and trust.
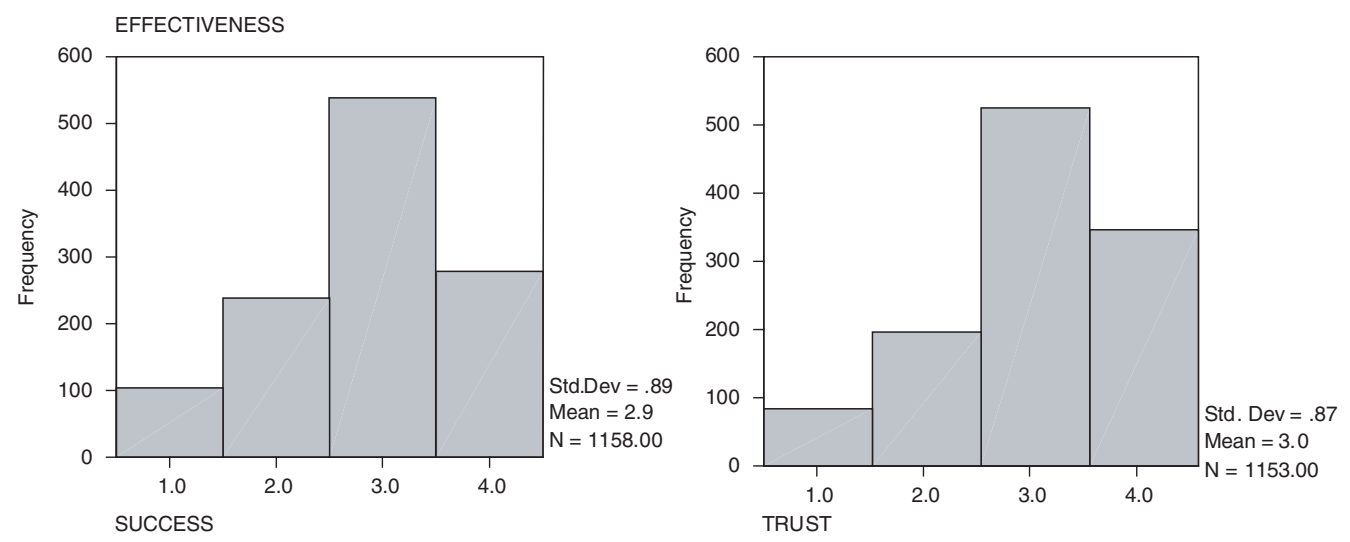

Fig. 1 Distribution of responses: effectiveness and trust
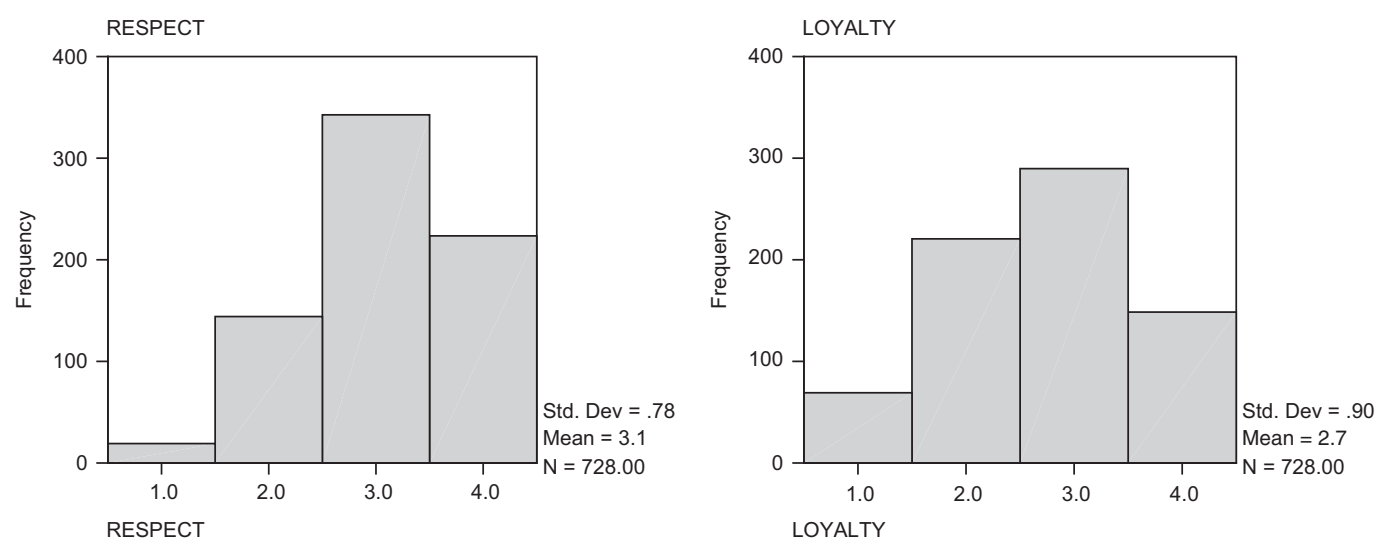

Fig. 2 Distribution of responses: respect and loyalty 
Figure 2 shows the respective distribution of responses for the variables respect and loyalty. Figures 1 and 2 demonstrate sufficiently large variance to indicate that investigation subjects were showing a range of responses and therefore were likely not to be self-censoring.

\subsection{Support for hypotheses}

Table 3 shows the results of the Spearman coefficient of correlation between trust, respect, loyalty, and effectiveness and identifies those that achieved significance at the 0.01 level. This analysis shows a strong, statistically significant correlation between effectiveness and trust, effectiveness and respect, and effectiveness and loyalty in this population sample. This evidence supports hypotheses $\mathrm{H} 1, \mathrm{H} 2$, and $\mathrm{H} 3$. The analysis shows that the strongest and equal strength of correlation is found between trust and loyalty and between respect and loyalty. Table 4 shows the relationship between effectiveness and social context, effectiveness and commonalty, and effectiveness and longevity.

The analysis shows a positive correlation between effectiveness and social context, effectiveness and commonalty, and effectiveness and longevity in this population sample. This evidence supports hypotheses H4, H5, and H6. Given the high degree of correlation between trust and effectiveness, it was not surprising to note that trust also significantly correlates with social context, commonalty, and longevity. While it would be useful to show whether the correlations differed by informant age, background, tenure, or professional level, for example, this type of data has not been collected routinely from the population sample thus far and is therefore not yet available for analysis.

Table 3 Correlations: effectiveness, trust, loyalty, and respect

\begin{tabular}{llll}
\hline & Effectiveness & Trust & Respect \\
\hline Trust & $0.61^{*}$ & & \\
Respect & $0.51^{*}$ & $0.56^{*}$ & \\
Loyalty & $0.55^{*}$ & $0.63^{*}$ & $0.63^{*}$ \\
\hline
\end{tabular}

$N=908 \quad{ }^{*} p \leqslant 0.01$

Table 4 Correlations: effectiveness, social context, commonalty, and longevity

\begin{tabular}{llll}
\hline & Effectiveness & Social context & Commonalty \\
\hline Social context & $0.15^{*}$ & & \\
Commonalty & $0.23^{*}$ & $0.53^{*}$ & \\
Longevity & $0.23^{*}$ & $0.31^{*}$ & $0.36^{*}$ \\
\hline$N=1009{ }^{*} p \leqslant 0.01$ & &
\end{tabular}

\section{DISCUSSION AND CONCLUSIONS}

The analysis of the results of the investigation clearly supports the hypotheses formulated at the outset of the investigation. For the population sample, this means that effective relationships within PD are strongly and significantly correlated with trust, respect, and loyalty. Associating effectiveness with trust has some research provenance and has been further supported by this research. However, the identification of loyalty and respect being as important as trust in relationship effectiveness is a new contribution that may be worthy of further investigation. Nonetheless, it is important to recognize that correlation does not imply causation and the actuality may lie in a circle of ongoing reinforcement between these and other factors: factors related to background, tenure or professional level, for example, that have not been investigated routinely alongside the main factors of this research. Thus, whether trust, respect, and loyalty are antecedents of an effective relationship or whether the opposite is true is difficult to establish.

The question must also be addressed as to how far the findings of the empirical investigation can be extended from this sample to PD activity in other contexts. As was alluded to above, the current investigation was carried out in two organizations that exhibit and maintain an open and approachable culture. The same access to subjects over such sensitive issues would not be forthcoming in every environment. Furthermore, the correlation between relationship effectiveness and the other identified network properties may not be the same in more closed environments. A second point to note is that the PD tasks in question were technically challenging and complex activities. Where tasks are not so complex, the need for a product developer to have effective relationships with other product developers may be less, and the importance of improving information flow and thus decision making may also be less.

The empirical research work presented in the present paper suggests that improved decision making during PD may be significantly served by improving levels of personal integrity in product developers. Previous work has indicated that organizational solution to improving information flow, and hence decision making, during PD should not be confined to alterations to formal structural units. Attempts to improve this must also take into account the importance of the network of relationships that create the social capital of the PD activity. This investigation has highlighted that improving social capital in PD, and making relationships between individuals more effective, will be enabled by raising levels of trust, respect, and loyalty. The investigation 
has also demonstrated significant correlation between effectiveness in a relationship during PD and the relationship's age and the commonalty of background in terms of how product developers define the wider social context of the relationship. This presents something of a conundrum for managers seeking to improve information flow, and hence PD decision making: none of these factors can be considered to lie in the direct control of PD management.

Given the use of single-item self-rating constructs employed by this research, it may also be construed of little surprise that the correlation pattern is demonstrably consistent around the '3's: the 'fairly' effective, 'fairly' trusting, 'fairly' loyal relationships, for example. It is important to recognize, however, that such consistency is a reflection of the aggregated response to the relationship properties being measured. Comparative review of ratings across individuals reveals greater diversity to that of team aggregates. Thus, while the results clearly support the hypotheses formulated at the start of the investigation, the findings also support identification of the following additional issues:

(a) the 'outliers': in particular, those responses at the lower extremes of relationship properties, the negative relationships, that may have a disruptive effect on the overall efficacy of the team's social dynamics;

(b) the differences in perception of mutual relationships, where such differences might lead to discontinuities, or could trigger discussion of causal factors that may assist to identify interventions and routes for improvement;

(c) potential conflict arising from the above: implicit or explicit conflict.

All of these points highlight the need for further research to identify interventions that can assist management to enhance PD relationships, in a way that is supported by researched practice concerning interventions. The next phase of the research, therefore, will undertake action research to encapsulate current findings in a theoretical framework that could be used to make managerial interventions in social capital and social networks to improve decision-making performance in PD.

\section{ACKNOWLEDGEMENT}

The authors would like to express their thanks to the Engineering and Physical Sciences Research Council for funding this research through the Loughborough University Innovative Manufacturing and Construction Research Centre.

\section{REFERENCES}

1 Eppinger, S. D. and Salimen, V. K. Patterns of product development interaction. In International Conference on Engineering design, ICED01, Glasgow, 21-23 August 2001, C586-288 (Professional Engineering Publishing, Bury St Edmunds and London).

2 Corbett, J. Design for economic manufacture. Ann. CIRP, 1986. 35(1), 93.

3 Pugh, S. Total Design, 1991 (Addison-Wesley, New York).

4 Li, S. and Davies, B. J. Key decisions in using information systems for strategic marketing decisions. Int. J. Mgmt Decision Making, 2001, 2(1), 16.

5 Albino, V., Pontrandolfo, P., and Scozzi, B. Analysis of information flows to enhance the coordination of production processes. Int. J. Prod. Econ., 2002(1-2), 75(1), 7-19.

6 Wijnberg, N. M., den Ende, J., and de Wit, O. Decision making at different levels of the organization and the impact of new information technology. Group Orgn Mgmt, 2002, 27(3), 408-430.

7 Snowden, D. Complex acts of knowing: paradox and descriptive self-awareness. J. Knowledge Mgmt, 2002, 6(2), 100-113.

8 Eppinger, S. D. Innovation at the speed of information. Harv. Bus. Rev., 2001, January 2001, Reprint R010L.

9 Simon, H. Administrative behaviour: a study of decision-making processes in administrative organizations, 1976 (Free Press, New York).

10 Galbraith, J. R. Organisation design, 1977, AddisonWesley, Reading, MA.

11 Knight, J. Organisations: an information systems perspective, 1979 (Wadsworth, Belmont, CA).

12 O'Leary-Kelly, S. W. and Flores, B. E. The integration of manufacturing and marketing/sales decisions: impact on organizational performance. J. Ops Mgmt, 2002, 20(3), 221-240.

13 Koufteros, X., Vonderembse, M., and Doll, W. Concurrent engineering and its consequences. J. Ops Mgmt, 2001, 19(1), 97.

14 McDonagh, E. An investigation into the factors contributing to the success of cross-functional teams. J. Prod. Innovation Mgmt, 2000, 17, 221-235.

15 Swink, M. Threats to new product manufacturability and the effects of development team integration processes. J. Ops Mgmt, 1999, 17(6), 691-709.

16 Sobek, D. K., Liker, J. K., and Ward, A. C. Another look at how Toyota integrates product development. Harv. Bus. Rev., 1998, 76(4), 36-48.

17 Cusumano, M. A. and Nobeoka, K. Thinking beyond lean: how multi-project management is transforming product development at toyota and other companies, 1998 (Free Press, New York).

18 Henderson, R. Managing innovation in the information age. Harv. Bus. Rev., 1994, Jan 1994, Reprint No 94105.

19 Nahapiet, J. and Ghoshal, S. Social capital, intellectual capital, and the organizational advantage. Acad. Mgmt Rev., 1998, 23(2), 242-266.

20 Cohen, D. and Prusak, L. How to invest in social capital. Harv. Bus. Rev., 2001, 79(6), 86-97. 
21 Ibarra, H. Network centrality, power and innovation involvement: determinants of technical and administrative roles. Acad. Mgmt J., 1993, 301, 471-501.

22 Krackhardt, D. and Hanson, J. R. Informal networks: the company behind the chart. Harv. Bus. Rev., 1993, 71(4), 104-111.

23 Bouty, I. Interpersonal and interaction influences on informal resource exchanges between $R \& D$ researchers across organizational boundaries. Acad. Mgmt, 2000, 43(1), 50-65.

24 Florida, R. The rise of the creative class and how it's transforming work, leisure, community and everyday life, 2002 (Basic Books, New York).

25 Hansen, M. T. The search-transfer problem: The role of weak ties in sharing knowledge across organization subunits. Admve Sci. Q., 1999, 44(1), 82-111.

26 Garguilo, M. and Bernassi, M. The dark side of social capital. In Corporate social capital and liability (Eds R. Leenders and S. M. Gabbay) 1999, (Kluwer, Boston).

27 Athaide, G. A. and Stump, R. L. A taxonomy of relationship approaches during product development in technology based, industrial markets. J. Prod. Innovation Mgmt, 1999, 16, 469-482.

28 Brookes, N. J., Smart, P. K., and Lettice, F. E. The importance of informal networks to effective design management. In 13th International Conference on Engineering design ICED 01, Design research - theories, methodologies and product modelling, Glasgow, 21-23 August 2001 (Professional Engineering Publishing, Bury St Edmunds and London).

29 Smart, P. K., Brookes, N. J., Lettice, F. E., Backhouse, C. J., and Burns, N. D. A boundary based view of product development: a feasibility study. Proc. Inst. Mech. Engrs, Part B: J. Engineering Manufacture, 2002, 216(B8), 1-12.

30 Morton, S. C., Smart, P. K., Brookes, N. J., and Lettice, F. E. From FTSE to KTSE - knowledge through social exchange. In European Operations Management Association 9th International Annual Conference: Operations management and the new economy, Copenhagen, 2002 (Copenhagen Business School, Aalborg University).

31 Meyerson, D., Weick, K. E., and Kramer, R. M. Swift trust and temporary groups. In Trust in organisations, 1996 (Sage Publications, Thousand Oaks).
32 Hardt, P. O. and Brynteson R. Swift trust, 1999 (Concordia University St. Paul, MN).

33 Jarvenpaa, S. L., Knoll, K., and Leidner, D. E. Is anybody out there? Antecedents of trust in global virtual teams. J. Mgmt Inf. Systems, 1998, 14(4), 29-64.

34 Jarvenpaa, S. L. and Staples, D. S. Exploring perceptions of organizational ownership of information and expertise. J. Mgmt Inf. Systems, 2001, 18(1), 151-183.

35 Brenkert, R. Conclusion: trust-conceptual aspects of a complex phenomenon. In Trust within and between organizations: conceptual issues and empirical applications, (Eds C. Lane and R. Bachman), 1998, pp. 298-323 (Oxford University Press, Oxford).

36 Thompson, D. (Ed.) The concise Oxford dictionary of current english, 9th edition, first edited by H. W. Fowler and F. G. Fowler, 1995 (Oxford University Press, Oxford).

37 Svenke, M. and Goslinga, S. The consequences of job insecurity for employers and unions: exit, voice and loyalty. J. Econ. Ind. Democracy, 2003, 24(2), 241.

38 Khatri, N. and Tsang, E. W. K. Antecedents and consequences of cronyism in organizations. J. Bus. Ethics, 2003, 43(4), 289-301.

39 Kanter, R. Leadership and the psychology of turnarounds. Harv. Bus. Rev., 2003, 81(6), 58.

40 Herzog, V. L. Trust building on corporate collaborative project teams. Prof. J. Proj. Mgmt, 2001, 32(1), 28-37.

41 Judd, C., Smith, E., and Kidder, L. Research Methods in Social Relations, 6th edition, 1991 (Academic Press, Holt, Rinehart, and Winston, New York).

42 Nunnally, J. C. Psychometric theory. 2nd edition, 1978, (McGraw-Hill, New York)

43 Morton, S. C. Characteristics of a managerial tool for harnessing the power of the informal organisation to improve product development performance. $\mathrm{PhD}$ Thesis, Innovative Manufacturing Research Centre, The Wolfson School of Mechanical and Manufacturing Engineering, Loughborough University, UK, 2004.

44 Oakshott, L. Essential quantitative methods for business, management and finance, 1998, (Macmillan Press Ltd, London). 